Fetal Diagnosis

and Therapy
Fetal Diagn Ther 2006;21:494-500

DOI: $10.1159 / 000095660$
Received: April 4, 2005

Accepted after revision: November 22, 2005

Published online: September 12, 2006

\title{
Amnion Cells Engineering: A New Perspective in Fetal Membrane Healing after Intrauterine Surgery?
}

\author{
Nikolaos A. Papadopulos ${ }^{a}$ Susanne Klotz $^{\mathrm{b}}$ Andreas Raith $^{\mathrm{c}}$ Matthias Foehn $^{\mathrm{d}}$ \\ Ulrike Schillinger ${ }^{c}$ Julia Henke ${ }^{c}$ Laszlo Kovacs $^{\text {a }}$ Raymund E. Horch ${ }^{\mathrm{e}}$ \\ Edgar Biemer ${ }^{a}$ \\ ${ }^{a}$ Department of Plastic and Reconstructive Surgery, Technical University of Munich; ${ }^{\mathrm{b}}$ Department of \\ Pediatric Cardiology and Congenital Heart Disease, Deutsches Herzzentrum, Munich; ${ }^{\mathrm{C}}$ Institute of \\ Experimental Oncology and Therapy Research, Technical University of Munich; ${ }^{d}$ Department of Plastic and \\ Hand Surgery, Albert Ludwig University, Freiburg, and d Department of Plastic and Hand Surgery, \\ Friedrich Alexander University, Erlangen-Nuremberg, Germany
}

\section{Key Words}

Fetoscopy $\cdot$ Fetal membranes $\cdot$ Premature rupture of membranes $\cdot$ Amnion cell $\cdot$ Tissue engineering

\begin{abstract}
In this study we aimed to set up an in vitro culture of the rabbit amnion in order to support in vivo fetal membrane healing capacity following fetoscopy. Fetal membranes were collected from a mid-gestational rabbit, and cultured on collagen support material for 14 days. 34 rabbits at 22-23 days gestational age (GA) underwent fetoscopy. The entry site was randomly allocated to 4 closure technique study groups: group I, human amnion membrane ( $n=23)$; group II, collagen foil $(n=16)$; group III, collagen
\end{abstract}

Supported by the Research Council of the Faculty of Medicine at the Technical University Munich (Konto für klinische Forschung der Medizinischen Fakultät der Technischen Universität München): KKF F 10-02/grant No. 8744553.

Presented at the 23rd Annual Meeting of the International Fetal Medicine and Surgery Society, Charleston, S.C., 2004.

\section{KARGER}

Fax +41613061234 E-Mail karger@karger.ch www.karger.com
(C) 2006 S. Karger AG, Basel $1015-3837 / 06 / 0216-0494 \$ 23.50 / 0$

Accessible online at: www.karger.com/fdt plug ( $n=19)$, and group IV, collagen plug with cultured amnion cells $(n=19)$. In all groups membrane access sites were additionally sealed with fibrin sealant, and the myometrium was closed with sutures. Fetal survival, amnion membrane integrity, and the presence of amniotic fluid were evaluated at 30 days GA. Cultures showed good survival in the collagen support material. Increased cellularity, survival and proliferations were observed. The amnion at the access site resealed in $58-64 \%$ of cases in groups II-IV, but none of the tested techniques was significantly better than the other. Histological examination indirectly revealed the anatomic repair of the membranes, since no entrapment of the membranes could be demonstrated in the myometrial wound.

Copyright (C) 2006 S. Karger AG, Basel

\section{Introduction}

Although endoscopic intrauterine surgery is gaining more and more acceptance for the treatment of different congenital malformations, iatrogenic preterm premature 
Table 1. Fetal outcome parameters (fetal survival, amniotic integrity, and amniotic fluid presence) at 30 days of gestational age

\begin{tabular}{|c|c|c|c|c|c|c|}
\hline \multirow[t]{2}{*}{ Treatment group } & \multicolumn{2}{|c|}{ Survival } & \multicolumn{2}{|c|}{ Amniotic integrity } & \multicolumn{2}{|c|}{ Amniotic fluid presence } \\
\hline & $\mathrm{n}$ & $\%$ & $\mathrm{n}$ & $\%$ & $\mathrm{n}$ & $\%$ \\
\hline Negative control group $(n=121)$ & $90 / 121$ & 74.7 & $79 / 90$ & 87.8 & $83 / 90$ & 92.2 \\
\hline Positive control group $(n=23)$ & $17 / 23$ & 73.9 & $9 / 17$ & $52.9 * *$ & $13 / 17$ & 76.5 \\
\hline Human amnion membrane (group I; $\mathrm{n}=23$ ) & $19 / 23$ & 82.6 & $5 / 19$ & $26.3^{* * *}$ & $9 / 19$ & $47.4^{*}$ \\
\hline Collagen foil (group II; $n=16$ ) & $14 / 16$ & 87.5 & $9 / 14$ & $64.3^{* *}$ & $11 / 14$ & 78.6 \\
\hline Collagen plug (group III; $\mathrm{n}=19$ ) & $17 / 19$ & 89.5 & $10 / 17$ & $58.8^{* *}$ & $11 / 17$ & $64.7 * *$ \\
\hline Collagen plug with amniotic cells (group IV; $n=19$ ) & $16 / 19$ & 84.2 & $10 / 16$ & $62.5^{* *}$ & $10 / 16$ & $62.5^{* *}$ \\
\hline
\end{tabular}

rupture of the membranes still remains its main limitation, although membrane trauma appears to be more minor than with the open approach [1]. Therefore, the investigation of an effective membrane closure technique is mandatory for the further development of intrauterine surgery, especially with a view to endoscopic surgery. Hence, different closure techniques have been proposed [2]. Nevertheless, only in the last years have these techniques been evaluated in various experimental models [3-8]. The pregnant rabbit appears still to be the most valuable experimental model toward a better understanding and evaluation of membrane closure techniques and healing $[4,5,9,10]$. With this model we recently demonstrated the best functional and anatomic membrane sealing after multilayer closure of uterine trauma following fetoscopy [11]. In the present study we suggest a further development of membrane closure techniques of fetoscopic access sites, proposing the combination of this highly promising multilayer closure with the in vitro culture of amnion cells on collagen support material, which was used also as a plug, in the same animal model.

\section{Materials and Methods}

34 time-dated pregnant New Zealand rabbits were housed 2 days prior to surgery. The housing was quiet, at normal room temperature and normal daylight. At 22-23 days gestational age (GA) the first operation was performed. After induction of anesthesia with $4-5 \mathrm{mg} / \mathrm{kg}$ propofol i.v. $\left(10 \mathrm{mg} / \mathrm{ml}\right.$, Propofol ${ }^{\circledR} 1 \%$ Fresenius Emulsion i.v., Fresenius Kabi Deutschland GmbH, Bad Homburg, Germany) and antibiotic prophylaxis with trimethoprim sulfadoxine $0.5 \mathrm{ml} / \mathrm{kg}$ s.c. (Borgal-Lösung ${ }^{\circledR} 7.5 \%$, Hoechst Roussel Vet Vertriebs $\mathrm{GmbH}$, Unterschleissheim, Germany), the animals were intubated and mechanically ventilated (Hallowell EMC Model AWS ${ }^{\circledR}$
Veterinary Anesthesia Workstation, Voelker GmbH, Kaltenkirchen, Germany). To achieve the desired blood propofol concentration during surgery, propofol $(20 \mathrm{mg} / \mathrm{ml})$ was given by a computer-programmed syringe driver $\left(1.5 \mathrm{mg} / \mathrm{kg} / \mathrm{min}\right.$ i.v., Perfusor ${ }^{\circledR}$ ED 1-300, Braun GmbH, Melsungen, Germany). Additional fentanyl $0.01 \mathrm{mg} / \mathrm{kg}$ i.v. $\left(0.5 \mathrm{mg} / \mathrm{ml}\right.$, Fentanyl ${ }^{\circledR} 0.5 \mathrm{mg}$ Curamed Injektionslösung, Dr. W. Schwabe GmbH \& Co., Abt. Curamed Pharma GmbH, Karlsruhe, Germany) and metamizol $50 \mathrm{mg} / \mathrm{kg} \mathrm{1:3} \mathrm{di-}$ lute with $\mathrm{NaCl}$ i.v. (Metalgin ${ }^{\circledR}$ Injektionslösung, Hexal $\mathrm{AG}$, Holzkirchen, Germany) were given as an analgesic component. Maternal heart rate and oxygen saturation were monitored with a pulse oximeter (Ohmeda, Helsinborg, Sweden) and the end-tidal $\mathrm{CO}_{2}$ concentration was displayed by a capnometer. The animals were positioned in the supine position and the abdomen was shaved, disinfected with povidone iodine and draped in a sterile way. Interventions on the uterus and membranes were done with an operation microscope (Carl Zeiss, Oberkochen, Germany, magnification $\times 5-25)$ and micro-instruments. Fetoscopy was done with a short, 1.2-mm, 10,000-pixel, $0^{\circ}$ fiber endoscope (Karl Storz, Tuttlingen, Germany) housed within a 14-gauge needle.

A midline abdominal incision was made to expose the pregnant uterus. First the gestational sacs were counted and numbered. Up to a maximum of one in two amniotic sacs were randomly assigned to 4 study groups, according to the closure technique that was to be tested $(n=77)$, excluding the gestational sacs above the cervix. The others served as positive $(\mathrm{n}=23)$, as well as negative controls $(\mathrm{n}=$ 121; table 1).

Under microscope vision and using micro-scissors a 2- to 3-mm myometrial incision was performed as already described [8] in order to separate the chorion and allow the amniotic membrane to bulge through the chorionic incision after gentle uterine pressure. The amniotic sac was then entered under microscopic control with the 14-gauge needle. Once in the amniotic cavity, the fetoscope was introduced into the needle to explore the amniotic cavity. During fetoscopy the fetal body, extremities, face, and tail, as well as the placenta or the umbilical cord were identified. The fetoscopy was limited to a maximum inspection time of $5 \mathrm{~min}$ with the use of up to $5 \mathrm{ml}$ Ringer lactate amniodistention infusion at body temperature. 
After withdrawal of the fetoscope, the access site was closed according to the study group (table 1$)$. In study group I $(n=23)$ the fetoscopic access site was covered with human amnion membrane (Tissue Bank of the German Institute for Cell and Tissue Replacement, Leipzig, Germany) and $0.3 \mathrm{ml}$ fibrin sealant was applied on the membrane defect area (Tissucol Duo S $2 \mathrm{ml} \mathrm{Immuno}{ }^{\circledR}$, Baxter Deutschland $\mathrm{GmbH}$, Unterschleissheim, Germany). In group II $(\mathrm{n}=16)$ the amnion membrane was covered with collagen foil (TissuFoil $\mathrm{E}^{\circledR}$, Baxter Deutschland $\mathrm{GmbH}$ ) and fibrin sealant. In group III $(n=19)$ the entry site was plugged with a collagen plug (TissuFleece $^{\circledR}$, Baxter Deutschland $\mathrm{GmbH}$ ) and fibrin sealant [11]. Prior to surgery, sterile dry collagen was precut and sized to the needle's lumen, with a maximal plug length of about $1 \mathrm{~cm}$. To position the plug we made a purpose-designed pusher of a few millimeters shorter than the length of the needle. After withdrawal of the fetoscope from the needle, a plug was loaded into the lumen. The plug and the custom-made pusher were inserted one after the other into the needle, advancing the plug exactly to the tip of the needle point. Once in place, the plug inflates by absorbing surrounding fluid, and locks the access site. In group IV $(n=19)$ the above-mentioned collagen plug was covered with in vitro cultured allogeneic amnion cells, and positioned into the amnion and chorion membrane defect, as well as covered with fibrin sealant, in the same way as in group III.

\section{Amnion Cell Isolation}

Amnion cells were isolated under sterile conditions 3 weeks prior to surgery from amnion membrane biopsies of mid-gestational pregnant rabbit. The fetal amnion membrane was harvested under aseptic conditions after euthanasia. The membrane was minced into small pieces. These pieces of fetal membrane were then immersed in $0.25 \%$ trypsin-EDTA (Biochrom AG, Berlin, Germany) in PBS-Dulbecco (Biochrom AG) for 20 min at $37^{\circ} \mathrm{C}$ with agitation. Subsequently, the cells were isolated by digestion with $0.02 \%$ clostridial collagenase (Roche AG, Mannheim, Germany) dissolved in Dulbecco's modified Eagle's medium (Gibco, Paisley, UK) supplemented with 10\% fetal calf serum (Gibco), $500 \mathrm{U}$ penicillin/500 ml, as well as $50 \mathrm{mg}$ streptomycin/500 $\mathrm{ml}$ (Biochrom AG, Berlin, Germany). The cells were cultured at $37^{\circ} \mathrm{C}$, and $5 \%$ $\mathrm{CO}_{2}$ in keratinocyte medium (Keratinocyte-SFM ${ }^{\circledR}$ \& supplements, bovine pituitary extract, h-EGF recombinant, Gibco).

7-10 days prior to surgery the isolated amnion cells were $90 \%$ confluent and were removed by $0.25 \%$ trypsin-EDTA treatment. Cells were counted (using a Neubauer-cell counting chamber) and vitality was determined by trypan blue staining. Afterwards, the cells were resuspended, and $1 \times 10^{6}$ cells in $1 \mathrm{ml}$ keratinocyte medium were injected into each collagen plug using a 1-ml syringe and a 22-gauge needle. Cells were injected to infiltrate different injection sites and to guarantee a regular spread of cells. Drainedoff cell suspension was seeded on the top of the collagen sponge. After 20 min of incubation, the dish was filled with 3-4 ml keratinocyte medium so that the top of the sponge was covered with medium. Then the collagen plugs, loaded with the cells, were incubated at $37^{\circ} \mathrm{C}$ and $5 \% \mathrm{CO}_{2}$ up to the time of implantation (fig. 1).

In all study groups the myometrial layers were closed microsurgically with a nylon 6/0 suture (Prolene ${ }^{\circledR}$, Ethicon GmbH, Norderstedt, Germany) [11]. 23 sacs were left unclosed (positive controls), and the 121 unmanipulated sacs served as negative controls.

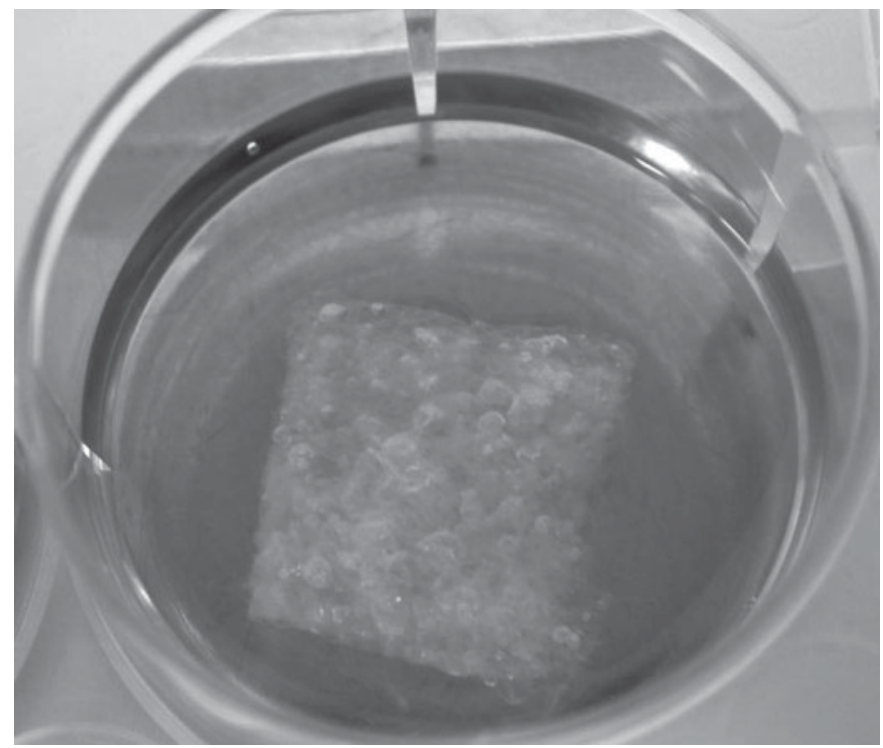

Fig. 1. Culture of amnion cells on the collagen support material (TissuFleece $\mathrm{E}^{\circledR}$ ) at $37^{\circ} \mathrm{C}$, and $5 \% \mathrm{CO}_{2}$ in keratinocyte medium.

After repositioning the uterus, the abdomen was closed in layers using polyglactin $3 / 0$ (Vicryl ${ }^{\circledR}$, Ethicon $\mathrm{GmbH}$ ) for the fascia and intracutaneous nylon $2 / 0$ suture (Ethilon ${ }^{\circledR}$, Ethicon $\mathrm{GmbH}$ ) for the skin. Postoperative uterine relaxation was achieved by administering $4.5 \mathrm{mg} / \mathrm{kg}$ medroxyprogesterone-acetate i.m. (Depo-Clinovir ${ }^{\circledR}$ $150 \mathrm{mg}$, Pharmacia \& Upjohn $\mathrm{GmbH}$, Erlangen, Germany). The animals were housed for the following 8 days under the same conditions as prior to surgery.

At 30 days $G A$ the pregnant rabbits were sacrificed with a pentobarbital injection, $60 \mathrm{mg} / \mathrm{kg}$ (Narcoren ${ }^{\circledR}$, Rhone-Merieux, Laupheim, Germany) to undergo a second-look laparotomy. A myometrial incision was made at the antimesenterial side, starting over the first cornual gestational sac [4]. The incision was extended over the full length of the horn, both over the treated as well as over the control sacs. Under microscopic control the myometrium was gently dissected with microsurgical instruments. The main outcome measurements were the integrity of amniotic membranes and the presence or absence of amniotic fluid. In case of an intact amniotic membrane, integrity was verified by an intra-amniotic injection of 5-10 ml saline solution dyed with methylene blue. The injection was given through the membrane, opposite to the fetoscopic access site with a 30-gauge needle. This way any leak eventually missed before could be visualized. The fetus was then delivered and it was noted whether the fetus was alive or not. The living fetuses were weighed and dissected to assess the wet fetal lung weight and to calculate the fetal lung to body weight ratio. Macerated stillborn fetuses were noted as non-surviving and not further included in statistical processing.

Statistics were done using the $\chi^{2}$ Fisher's exact two-tailed test for nominal variables and ANOVA for continuous variables using the SPSS 12.0 for Windows software package (SPSS Inc., Chicago, Ill., USA). 

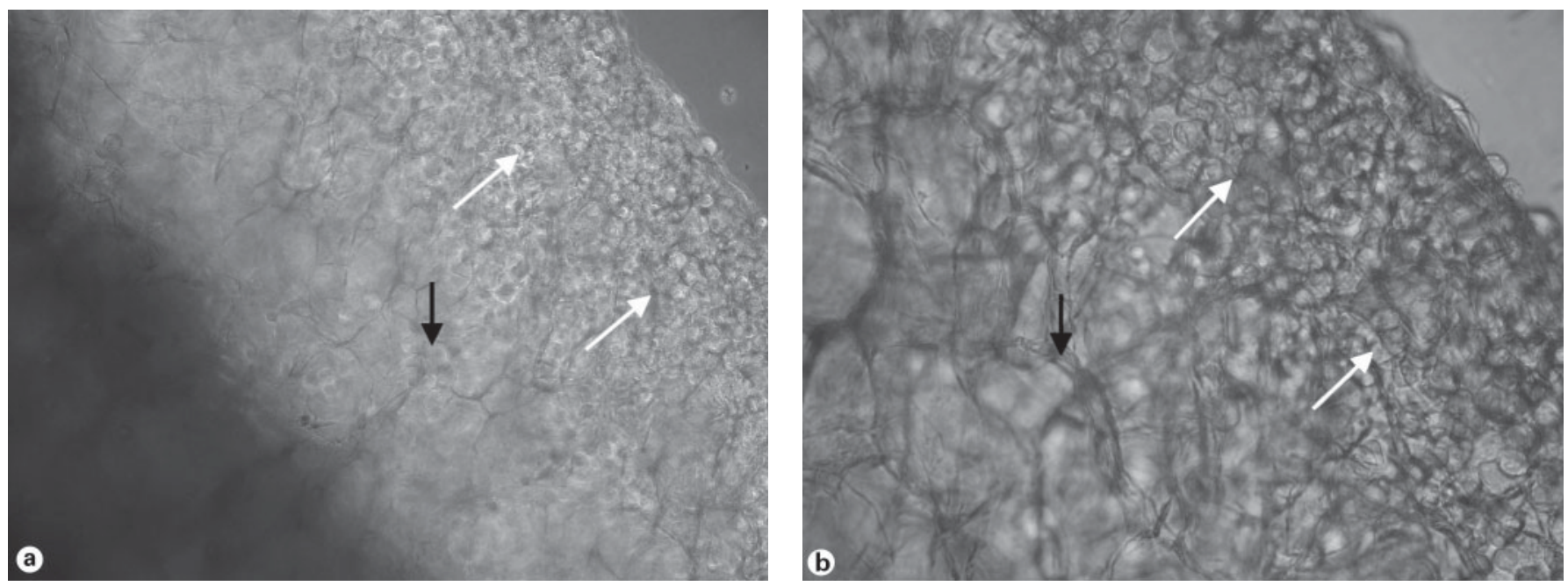

Fig. 2. Vital amnion cells adherent (white arrow) on the collagen sponge matrix (black arrow; TissuFleece ${ }^{\circledR}$ ). Original magnifications: $\mathbf{a} \times 10 ; \mathbf{b} \times 40$.

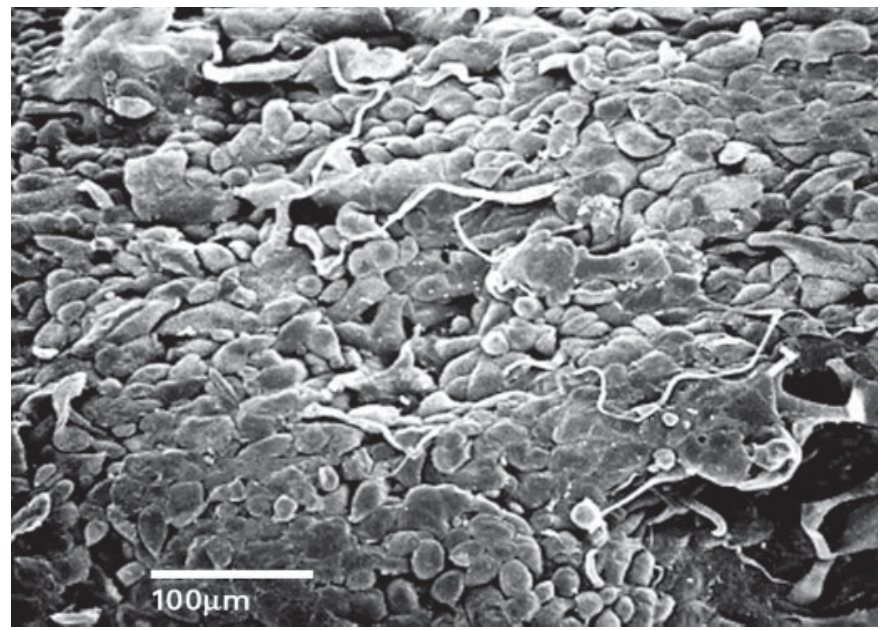

Fig. 3. 10 days after seeding the isolated amnion cells, an almost confluent layer of amnion cells firmly attached to the collagen support material (TissuFleece $\mathrm{E}^{\circledR}$ ) can be seen. SEM. Original magnification $\times 240$. Bar $=100 \mu \mathrm{m}$.

\section{Results}

Amnion cell cultures showed good survival in the collagen support material (fig. 2). Increased cellularity, survival and proliferations were observed (fig. 3). No adverse effects on animal pregnancy and the fetus could be documented after the use of in vitro cultured amnion cells in the collagen plugs (group IV).
Fetal survival was similar in the study groups except in the positive and negative control group (table 1).

The integrity of the amniotic membranes of unmanipulated sacs near term was $87.8 \%$. After fetoscopy without any attempt to close the membranes (positive control group) the amniotic integrity rate 7 days later was $52.9 \%$. The use of human amnion membrane combined with fibrin sealant and myometrial suture (group I) did not improve the amniotic integrity rate compared to that of the positive control group at second-look operations. In group II (Collagen foil ${ }^{\circledR}$, Tissucol ${ }^{\circledR}$ and myometrial suture) the integrity of fetal membranes was $64.3 \%$, and $58.8 \%$ in group III (Collagen plug, Tissucol ${ }^{\circledR}$ and myometrial suture). The use of the collagen plug in combination with in vitro cultured amniotic cells improved the integrity of fetal membranes to $62.5 \%$ (group IV).

The presence of amniotic fluid differs according to the results of amnion membrane integrity. In absolute numbers, collagen foil showed the best result with $78.6 \%$, while covering the access site with human amnion membrane resulted in only $47.4 \%$ amniotic integrity.

Fetal lung/body weight ratio of unmanipulated sacs with intact membranes and treated gestational sacs (positive control and study groups: $n=83$ ) was compared with intact and ruptured membranes. Fetal lung and body weights of fetuses from gestational sacs with unmanipulated membranes and treated groups with intact membranes were similar, and higher than in fetuses from treated gestational sacs with ruptured membranes. The fetal 
Table 2. Comparison of fetal lung/body weight ratio according to integrity of amnion (mean \pm SD)

\begin{tabular}{|c|c|c|c|}
\hline & \multirow{2}{*}{$\begin{array}{l}\text { Negative control } \\
\text { group }(n=79)\end{array}$} & \multicolumn{2}{|l|}{ Treatment groups } \\
\hline & & $\begin{array}{l}\text { sacs with intact } \\
\text { membranes }(n=43)\end{array}$ & $\begin{array}{l}\text { sacs with ruptured } \\
\text { membranes }(n=40)\end{array}$ \\
\hline Body weight, g & $31.35 \pm 11.731$ & $31.64 \pm 9.887$ & $29.47 \pm 11.987$ \\
\hline Lung weight, $\mathrm{g}$ & $1.29 \pm 0.510$ & $1.25 \pm 0.447$ & $1.08 \pm 0.423^{*}$ \\
\hline Fetal lung/body weight ratio & $0.0412 \pm 0.00651$ & $0.0394 \pm 0.00667$ & $0.0369 \pm 0.00710^{*}$ \\
\hline
\end{tabular}

lung/body weight ratio between the treated groups with ruptured membranes and the negative control group with amnion integrity were statistically different $(\mathrm{p}<0.05$, table 2).

The histological examination of the access sites indirectly revealed the anatomic repair of the membranes as no entrapment of fetal membranes could be confirmed in the myometrial wound (fig. 4).

\section{Discussion}

After the first successful intrauterine intervention in the pregnant guinea pig animal model [12], intensive development of pioneering methods for prenatal diagnosis [13], as well as pre-, intra-, and postoperative management to maximize feto-maternal survival, only recently began in the last decades of the 20th century [14]. Today, high-resolution ultrasound, magnetic resonance imaging (MRI), and other diagnostic procedures allow an earlier and more precise intrauterine diagnosis of congenital anomalies [15], and even their intrauterine treatment has become reality. Therefore, prenatal treatment can nowadays be considered as a treatment option not only for life-threatening malformations but also for non-lifethreatening anomalies like spina bifida [16-18]. Moreover, recent advances in endoscopic interventions have allowed a safer intrauterine approach to the fetus, thereby increasing the number of centers performing such interventions, although the risk of preterm premature rupture of the membranes and preterm labor exists [1]. Although the prospects for fetal treatment of non-lifethreatening disorders such as craniofacial malformations are still unclear, their intrauterine treatment will depend upon whether and when the known complications of

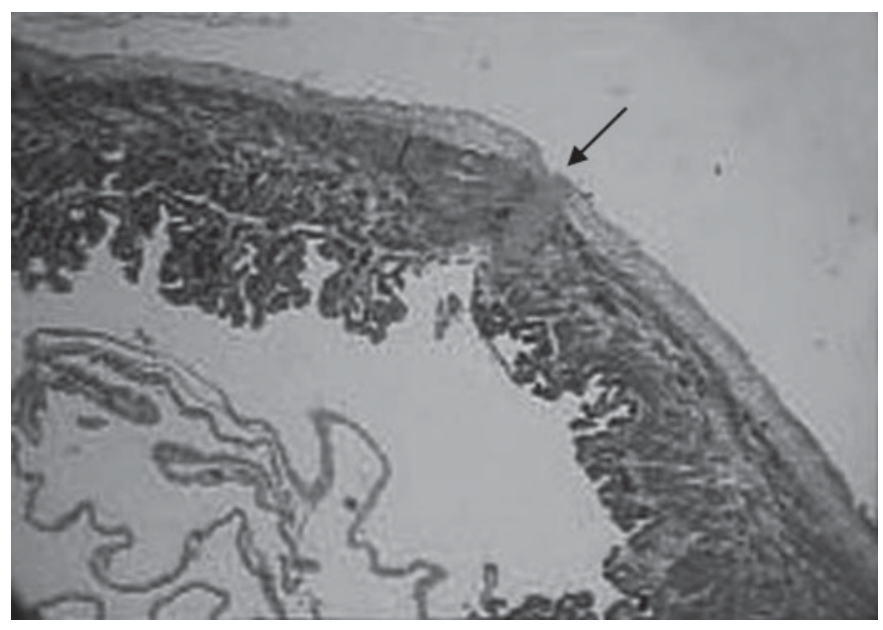

Fig. 4. Van Gieson staining of the access site of treatment group IV. Evidence of scar tissue in the myometrial wound (arrow), but no entrapment of the fetal membranes, representative of all amnion sacs in which fetoscopy was performed, followed by myometrial suture. Lower left site: Presence of the membranes at the central part of the amniotic sac. Original magnification $\times 4.5$.

these invasive procedures (amniotic fluid leakage, membrane disruption, and oligohydramnios) can be treated satisfactorily $[19,20]$.

For these reasons, the mid-gestational rabbit was proposed as the first animal model to investigate fetal membrane healing after hysterotomy and fetoscopic exploration of the amniotic sac $[4,5,8-11]$. In the meantime, this model has been established as the gold standard for this kind of study, and will surely contribute substantially toward the further development of intrauterine surgery. 
Consequently, in the animal model mentioned, our laboratory modified the previously described multilayer surgical closure technique of the fetal membranes [11], introducing for the first time as an additional option the in vitro culture of amnion cells and their utilization on collagen support material, which could likewise be used as a plug. This combination of a collagen plug for the fetal membranes with in vitro cultured amnion cells and fibrin sealant as well as myometrium closure with sutures following fetoscopy was found to be reproducible and achieved the promising goals we expected with regard to anatomic healing of the membrane defects. In our opinion this method is presently the most encouraging one, and can surely be developed further considering the learning curve of such a new technique in our hands. Therefore, we speculate that further improvement in the in vitro culture of the amnion cells would result in better sealing rates of the fetal membranes after endoscopic fetal surgery. Additionally, as the 'pure' plug technique (group IV), this method is applicable to percutaneous interventions as well.

Nevertheless, further experimental studies are obligatory, not only in order to investigate possible postoperative complications using these collagen plugs to seal the iatrogenic rupture of membranes, but also to better understand the biology of the amnion cells and their healing process, and to further develop this technique in order to achieve safe and excellent surgical results. Only under such conditions will it be possible in the future to clinically assist the human fetus in a wider manner and, therefore, also those with non-life-threatening malformations such as the craniofacials $[19,20]$.

\section{Conclusions}

This animal culture system represents a new model for the study of fetal membrane repair after iatrogenic defect. Despite the good survival and localized proliferation observed in the collagen support material, no obvious statistically better closure of fetoscopy-induced permanent membrane defects was seen under the conditions described. Therefore, additional research is needed to further explore the mechanisms of in vitro culture of fetal membranes on support materials, as well as the use of other possible support materials to improve fetal membrane healing following iatrogenic trauma.

\section{Acknowledgments}

We wish to thank all the members of the intrauterine surgery team at the Technical University of Munich, Mrs. R. Bergmeyr, Dr. P. Böttcher, Prof. Wolf Erhardt, Prof. H. Feussner, Mrs. R. Hertel, Mrs. M. Leucz, Prof. M.A. Papadopoulos, Mrs. V. Pohlheimer, and Prof. H.F. Zeilhofer, for their efforts to set up the fetal membrane healing project, for their clinical and experimental input, as well as for reviewing the manuscript and their fruitful discussions. The authors also wish to thank Mrs. Storz-Reling, Mrs. S. Schmid, and Mr. G. Steinrücken (Karl Storz-Endoskope Germany); Baxter Germany - Immuno GmbH; Mr. G. Hess, Mr. M. Riedl, Mr. J. Scholz, and Mr. A. Sowa (Ethicon GmbH, Germany), and Mrs. C. Syring and Dr. R. von Versen (Deutsches Institut für Zell- u. Gewebeersatz) for their support.

\section{References}

1 Papadopulos NA, Deprest JA, Dumitrascu I, Miserez M, Yesildaglar N, Vandenberghe K, Lerut TE: Endoskopische fetale Chirurgie: eine neue Perspektive in der fetalen Therapie? Sozialpädiatr Kinder Jugendheilkd 2000;22:1422.

2 Mercer BM: Preterm premature rupture of the membranes. Obstet Gynecol 2003;101:178193.

3 van der Wildt B, Luks FI, Steegers EAP, Deprest J, Peers KHE. Absence of electrical uterine activity after endoscopic access for fetal surgery in the rhesus monkey. Eur J Obstet Gynecol Reprod Biol 1995;58:213-214.
4 Papadopulos NA, Van Ballaer PP, Ordonez JL, Laermans I, Vandenberghe K, Lerut T, Deprest JA: Fetal membrane closure techniques after hysteroamniotomy in the midgestational rabbit model. Am J Obstet Gynaecol 1998;178: 938-942.

5 Deprest JA, Papadopulos NA, Decaluwé H, Yamamoto H, Lerut TE, Gratacós E: Closure techniques for fetoscopic access sites in the rabbit at midgestation. Hum Reprod 1999; 14: 1730-1734.

6 Luks FI, Deprest JA, Peers KH, Steegers EA, van der Wildt B: Gelatine sponge plug to seal fetoscopy port sites: technique in ovine and primate models. Am J Obstet Gynecol 1999; 181:995-996.
7 Cortes RA, Townsend T, Lee H, Farmer D, Nobuhara K, HarrisonM: A porcine model for prevention of preterm membrane separation in fetal surgery (abstract). 23rd Annu Meet International Fetal Medicine and Surgery Society, Charleston, 2004.

8 Papadopulos NA, Dumitrascu I, Ordonez JL, Decaluwe H, Lerut T, Barki G, Deprest JA: Fetoscopy in the pregnant rabbit at mid-gestation. Fetal Diagn Ther 1999;14:118-121.

9 Gratacós E, Yamamoto H, Papadopulos NA, Adriaenssens T, Philips T, Lerut TE, Deprest JA: The mid-gestational rabbit as a model for the creation of membrane defects following needle fetoscopy. Am J Obstet Gynecol 1999; 180:1263-1267. 
10 Gratacós E, Wu J, Yesildaglar N, Devlieger R, Pijnenborg R, Deprest JA: Successful sealing of fetoscopic access sites with collagen plugs in the rabbit model. Am J Obstet Gynecol 2000; 182:142-146.

11 Papadopulos NA, Klotz S, Raith A, Henke J, Kloeppel M, Brill T, Müller D, Kovacs L, Erhardt W, Biemer E: Chirurgische Verschlussmethoden von fetoskopisch erzeugten Membrandefekten am mittelträchtigen Kaninchenmodell. Geburtsh Frauenheilkd 2003;63: 651-657.

12 Mayer A: Ueber die Möglichkeit operativer Eingriffe beim lebenden Saugtierfötus. Zentralbl Gynaekol 1918;42:773-775.

13 Christ JE, Meininger MG: Ultrasound diagnosis of cleft lip and cleft palate before birth. Plast Reconstr Surg 1981;68:854-859.
14 Harrison MR, Anderson J, Rosen MA, Ross NA, Hendrickx AG: Fetal surgery in the primate. I. Anesthetic, surgical, and tocolytic management to maximize fetal-neonatal survival. J Pediatr Surg 1982;17:115-122.

15 Papadopoulos MA, Christou PK, Athanasiou AE, Boettcher P, Zeilhofer HF, Sader S, Papadopulos NA: Three-dimensional craniofacial reconstruction imaging. Oral Surg Oral Med Oral Pathol Oral Radiol Endod 2002;93:382393.

16 Bruner JP, Tulipan NE, Richards WO: Endoscopic coverage of fetal open myelomeningocele in utero. Am J Obstet Gynecol 1997; 176: 256-257.
17 Adzick NS, Sutton LN, Cromblehome TM, Flake AW: Successful fetal surgery for spina bifida. Lancet 1998;352:1675-1676.

18 Farmer DL, von Koch CS, Peacock WJ, Danielpour M, Gupta N, Lee H, Harrison MR: In utero repair of myelomeningocele: experimental pathophysiology, initial clinical experience, and outcomes. Arch Surg 2003;8:872-878

19 Papadopulos NA, Papadopoulos MA: Can intrauterine surgery improve the quality of life of cleft lip and palate patients? Hippokratia 2003; 2:107-129.

20 Papadopulos NA, Papadopoulos MA, Kovacs L, Zeilhofer HF, Henke J, Boettcher P, Biemer E: Fetal surgery and cleft lip and palate: Current status and new perspectives. Br J Plast Surg 2005;58:593-607. 